\title{
Designer ubiquitin proteins towards controlling calcium carbonate crystallization
}

\author{
CRistina RUIZ-AGUdO ${ }^{1}$, JOACHIM LUTZ ${ }^{1}$, MiCHAEL \\ $\mathrm{KING}^{1}$, ANDREAS MARX ${ }^{1}$, DENIS GEBAUER ${ }^{2}$
}

1'cristina.ruiz-agudo@uni-konstanz.de

University of Konstanz, Universitätsstrasse 10

78457 Konstanz (Germany)

22gebauer@acc-uni-hannover.de

Proteins controlling mineralization in vivo are diverse, suggesting that there are various ways by which mineralization can be directed in bio-inspired approaches ${ }^{[1]}$. While well-defined three-dimensional (3D) structures occur in biomineralization proteins, the design of synthetic macromolecules with specific, reproducible and predictable $3 \mathrm{D}$ arrangements of mineral-interacting functions poses an ultimate challenge. In this context, we used genetically engineered Ubiquitin $(\mathrm{Ub})$ proteins in order to overcome the limitations of generic additive systems. Indeed, $\mathrm{Ub}$ with three phosphate functions at defined positions shows unique effects, based on a yet unmatched capability towards the stabilization of a film of a $\mathrm{CaCO}_{3}$ dense liquid mineral phase visible even by naked eye, its transformation into amorphous nanoparticles, and subsequently crystals with complex shapes. ${ }^{[2]}$ In addition, different 3D-arrangment of the phosphate functions within the Ub protein have been proposed by computational methods and studied experimentally regarding the formation of this $\mathrm{CaCO}_{3}$ dense liquid phase.

Herein, we presents designer proteins, as a unique, new generation of crystallization additives where the 3D arrangement of mineral-interacting functions can be designed at will, promising a future use for programmable, targetoriented mineralization control.

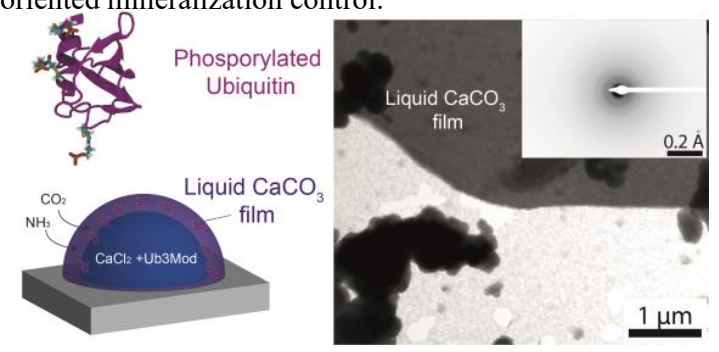

[1] S. Weiner, I. Sagi, L. Addadi, Science 2005, 309, 1027.

[2] C. Ruiz-Agudo, J. Lutz, P. Keckeis, M. King, A. Marx, D. Gebauer, J. Am. Chem. Soc. 2019, 141, 31, 12240. 